\title{
Familial myelofibrosis
}

\author{
C A SIEFF AND P MALLESON \\ Department of Haematology, The Hospital for Sick Children, Great Ormond Street, London
}

SUMmaRY Two siblings developed a fulminant fatal myeloproliferative disease at 7 and 8 weeks of age. The illness presented with pallor, haemorrhagic symptoms, and hepatosplenomegaly, and the blood picture was that of pancytopenia and leucoerythroblastosis. Bone marrow histology showed reduced haemopoiesis with generalised fibrosis. Histiocytes were present, but haemophagocytosis was not prominent. There was evidence of extramedullary haemopoiesis in the spleen, with a chronic inflammatory infiltrate of other organs. The condition closely resembles acute idiopathic myelofibrosis of infancy, but the early onset with severe pancytopenia and the histological appearances may arouse suspicion of the possible familial nature of the condition. Although clinically resembling familial haemophagocytic reticulosis, the uncharacteristic bone marrow, liver, and spleen histology serve to exclude this diagnosis.

Myelofibrosis is a myeloproliferative disease characterised by proliferation of haemopoietic cells, a variable degree of bone marrow fibrosis, a typical 'leucoerythroblastic' blood picture, and myeloid metaplasia of the liver, spleen, and occasionally, of other organs. It occurs most commonly in middleaged and elderly persons in whom the onset is nearly always insidious, with a prolonged course. In contrast to this the childhood form is rare, and often acute, with rapidly progressive bone marrow failure. In older children it is generally secondary to acute leukaemia ${ }^{1-7}$ or lymphoma, ${ }^{8-9}$ but in infants it is often idiopathic. ${ }^{18-12}$ We report a fulminant myeloproliferative disorder occurring in two siblings, and discuss the differential diagnosis and implications for genetic counselling of the condition.

\section{Case reports}

Case 1. A girl, the second child of healthy parents (the paternal grandparents were 2nd-cousins), was born at 36 weeks' gestation after an uncomplicated pregnancy. A 4-year-old brother was healthy. She had been well until 8 weeks of age when pallor and hepatosplenomegaly were noted. $\mathrm{Hb}$ was $5.7 \mathrm{~g} / \mathrm{dl}$, white blood count (WBC) $3.9 \times$ $10^{9} / 1$ with $0.9 \times 10^{9} / 1$ neutrophils, a few metamyelocytes, and $2 \cdot 5$ normoblasts per 100 WBC (Table 1 ). A bone marrow aspirate was cellular. Antibody titres to cytomegalovirus, rubella, measles, mumps, herpes simplex, and varicella zoster were normal, as were serological tests for syphilis, and the toxoplasma dye test.
On examination at 12 weeks, she had a head circumference $<3$ rd centile, mild right hemihypertrophy, and a mongoloid slant to the palpebral fissures; she was pale, with multiple bruises over the trunk. The liver was enlarged $6 \mathrm{~cm}$ and the spleen $9 \mathrm{~cm}$ below the costal margin. There was no lymphadenopathy. Blood count showed anaemia, thrombocytopenia, and neutropenia with leucoerythroblastic features (Table 1). Bone marrow from two different sites was extremely difficult to aspirate and was hypocellular with reduced granulopoiesis, erythropoiesis, and platelet production. Blast cells were not increased and there was no malignant cell infiltration. The aspirate was negative for tuberculosis on culture and immunofluorescence testing. A bone marrow trephine was hypocellular and showed increased reticulin deposition. Chromosome analysis showed a 46XX karyotype. Serum IgM was $126 \mathrm{IU} / \mathrm{ml}$ (increased), IgA $38 \mathrm{IU} / \mathrm{ml}$ and $\mathrm{IgG}$ $75 \mathrm{IU} / \mathrm{ml}$ (normal), antinuclear factor negative, $\mathrm{HbF}$ $3 \%$, and random urine screen negative for mucopolysaccharides.

She developed multiple staphylococcal abscesses and became increasingly ill. Treatment was started with intravenous antibiotics but her condition continued to deteriorate with the onset of generalised convulsions. She died 2 weeks after admission and 6 weeks after the onset of the illness.

Case 2. A boy, born at term. He had been well until aged 7 weeks when he became pale and anorectic, and developed opisthotonic posturing; his development had regressed also. 


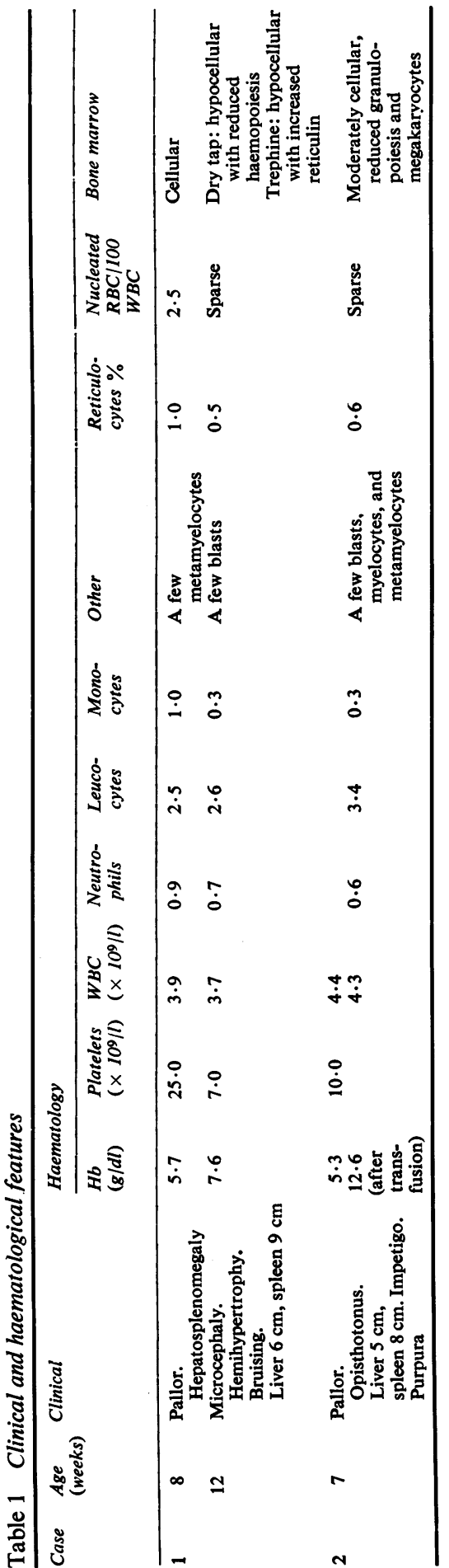

On examination, he was a very unwell pale baby with a purpuric rash on the trunk and limbs. There were impetigenous lesions on the trunk, and he had severe purulent rhinitis. The liver was palpable $5 \mathrm{~cm}$ and the spleen $8 \mathrm{~cm}$ below the costal margin; there was no lymphadenopathy.

$\mathrm{Hb}$ was $5 \cdot 3 \mathrm{~g} / \mathrm{dl}$, WBC $4.4 \times 10^{9} / 1$, platelets $10 \times 10^{9} / 1$, and a blood film showed sparse nucleated red blood cells (Fig. 1), myelocytes, and metamyelocytes (Table 1). Bone marrow was difficult to aspirate and showed moderately cellular smears with active erythropoiesis and reduced granulopoiesis. Megakaryocytes were scanty, histiocytes normal, and there was no increase in blasts or evidence of malignant infiltration. Trephine biopsy was cellular and confirmed the reduction of megakaryocytes and myeloid precursors, and showed a pronounced increase in reticulin. Chromosome analysis of blood and bone marrow cells was normal.

Liver function tests showed slightly raised transaminases (ALT 34 IU/1, AST 92 IU/1); bilirubin was $16 \mu \mathrm{mol} / 1(0.9 \mathrm{mg} / 100 \mathrm{ml})$. Serum $\operatorname{IgA}$ and $\operatorname{IgM}$ were normal (31 IU/1 and $25 \mathrm{IU} / 1)$, and IgG was slightly reduced (47 IU/l). Skeletal survey showed no evidence of osteosclerosis but vertebral bodies had a 'bone within bone' appearance. The following investigations were normal: toxoplasma dye test, Venereal Disease Research Laboratory and treponemal haemagglutinination test, cytomegalovirus,

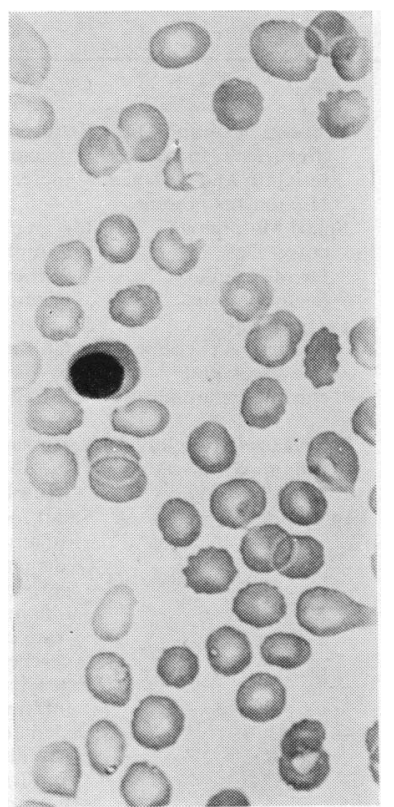

Fig. 1 (Case 2.) Blood showing poikilocytes and a normoblast. $\times 400$. 
EB virus antibody screen, rubella and herpes simplex complement-fixation tests, urine and plasma aminoacid chromatograms, C3 and total haemolytic complement, antinuclear factor, plasma copper and zinc, white cell $\beta$-galactosidase, fucosidase, monosidase, and plasma $\beta$-glucuronidase. On the fifth day after admission, intravenous antibiotics were begun because of neutropenia and intermittent pyrexia. It was apparent that this child had a condition identical with that of his sister and in an attempt to influence the expected outcome of the illness, he was treated with vincristine $1.5 \mathrm{mg} / \mathrm{m}^{2}$ on day 1 , and prednisolone $80 \mathrm{mg} / \mathrm{m}^{2}$ daily. Although his condition initially improved slightly, he subsequently developed diarrhoea and required nasogastric feeding. On day 15 , he began passing blood per rectum and his condition deteriorated with increasing jaundice, ascites, and oedema. He died 4 days later, 3 weeks after the onset of the illness.

\section{Necropsy}

Findings were similar in both infants (Table 2). Bone marrow showed reduced haemopoiesis and an increase in reticulin and collagen (Figs 2, 3, and 4). Histiocytes were present but haemophagocytosis was not prominent. Extramedullary haemopoiesis was present in the spleen and the liver showed fatty

Table 2 Necropsy findings

\begin{tabular}{|c|c|c|}
\hline & Case 1 & Case 2 \\
\hline Bone marrow & $\begin{array}{l}\text { Reduced haemopoietic } \\
\text { precursors. Increased } \\
\text { reticulin and collagen. } \\
\text { Histiocytes present }\end{array}$ & $\begin{array}{l}\text { Reduced haemopoietic } \\
\text { precursors. Diffuse } \\
\text { increase in reticulin }\end{array}$ \\
\hline Spleen & $\begin{array}{l}\text { Small Malpighian } \\
\text { corpuscles. } \\
\text { Extramedullary } \\
\text { haemopoiesis }\end{array}$ & $\begin{array}{l}144 \text { g enlarged. } \\
\text { Lymphoid depletion. } \\
\text { Extramedullary } \\
\text { haemopoiesis }\end{array}$ \\
\hline Liver & $\begin{array}{l}\text { Fatty change. } \\
\text { Portal tracts connec- } \\
\text { tive tissue and } \\
\text { chronic inflammation }\end{array}$ & $\begin{array}{l}33 \mathrm{~g} \text { fatty and congested. } \\
\text { Chronic inflammation } \\
\text { of portal tracts. } \\
\text { Infrequent haemo- } \\
\text { phagocytosis }\end{array}$ \\
\hline Lymph nodes & $\begin{array}{l}\text { No reactive follicles. } \\
\text { Inflammatory cells }\end{array}$ & $\begin{array}{l}\text { Lymphadenopathy. } \\
\text { No follicles. } \\
\text { Lymphocyte depletion }\end{array}$ \\
\hline Kidney & Inflammatory cells & $\begin{array}{l}\text { Small foci of chronic } \\
\text { inflaınmation }\end{array}$ \\
\hline Brain & - & $\begin{array}{l}\text { Oedematous meninges, } \\
\text { perivascular } \\
\text { inflammatory infil- } \\
\text { trate cerebrum and } \\
\text { cerebellum }\end{array}$ \\
\hline Pancreas & - & $\begin{array}{l}\text { Extensive inflammatory } \\
\text { infiltration }\end{array}$ \\
\hline Lungs & - & $\begin{array}{l}\text { Oedematous with } \\
\text { vascular congestion } \\
\text { and focal pulmonary } \\
\text { haemorrhage }\end{array}$ \\
\hline $\begin{array}{l}\text { Gastrointestinal } \\
\text { tract }\end{array}$ & 一 & $\begin{array}{l}\text { Diffuse dilatation. } \\
\text { Extensive mucosal } \\
\text { haemorrhagic necrosis }\end{array}$ \\
\hline
\end{tabular}

changes with portal tract infiltration by chronic inflammatory cells. Haemophagocytosis was sparse. Kidneys showed chronic inflammatory cell infiltration as did the testes (Case 2), pancreas, and brain.

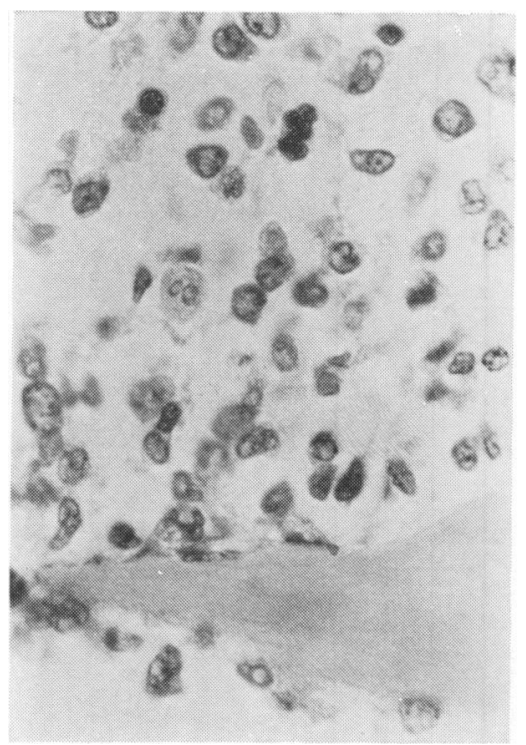

Fig. 2 (Case 1.) Bone marrow showing histiocytes and haemopoietic precursors. Giemsa $\times 400$.

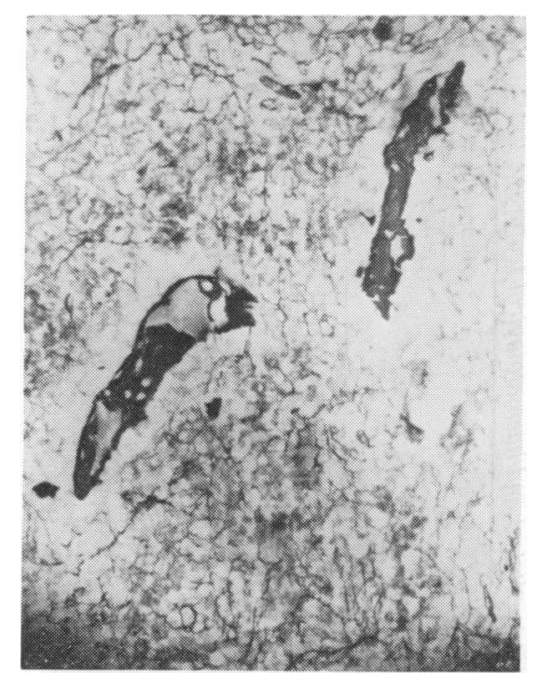

Fig. 3 (Case 1.) Bone marrow showing increased reticulin deposition. $\times 100$. 


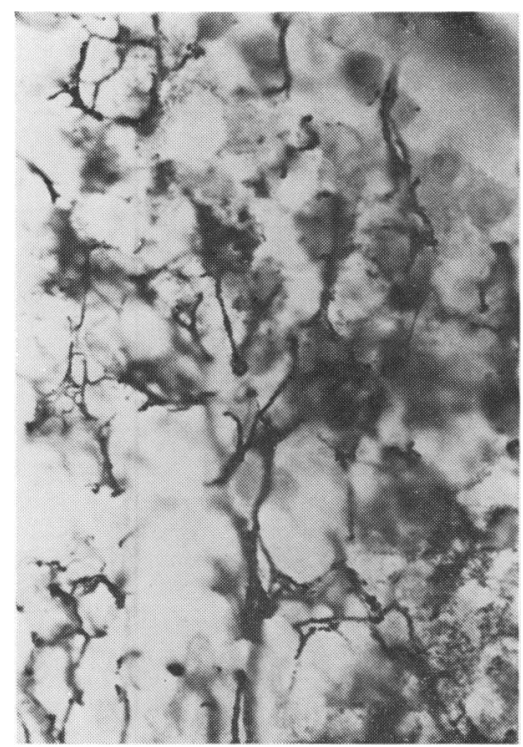

Fig. 4 (Case 1). Bone marrow showing heavy reticulin deposition. $\times 400$.

\section{Discussion}

These siblings suffered from a fulminant, fatal illness characterised by the onset at 7-8 weeks of pallor, haemorrhagic symptoms, and hepatosplenomegaly. The blood picture was that of pancytopenia with leucoerythroblastosis, and the bone marrow was hypocellular with increased reticulin and collagen deposition. Haemophagocytosis, although present, was not a prominent feature. There was extramedullary haemopoiesis in the spleen, with infiltration of liver, meninges, kidneys, pancreas, and (in Case 2 ) the testes by mixed chronic inflammatory cells.

The familial nature, early onset, and presentation with symptoms of bone marrow failure and hepatosplenomegaly suggest a diagnosis of familial haemophagocytic reticulosis. This condition was first described by Farquhar and Claireaux ${ }^{13}$ and is characterised by early onset of irritability, recurrent fever, pallor, and hepatosplenomegaly. This is associated with rapidly progressive pancytopenia, and neurological complications due to meningo-encephalitis may occur. The course is generally fatal within a few weeks or several months, with jaundice and haemorrhage frequent terminal events. The most striking histological feature is phagocytosis of erythroid, and sometimes myeloid precursors by histiocytes infiltrating bone marrow, liver portal tracts, and sinusoids, splenic sinuses, and sometimes, other organs. Diagnosis may be difficult during life, as biopsy specimens do not always show evidence of haemophagocytosis. However, microscopical examination at necropsy usually enables a firm diagnosis to be made.

Although the clinical features of these two siblings suggested familial haemophagocytic reticulosis, histology at necropsy did not show prominent haemophagocytosis in reticuloendothelial organs, and the increased bone marrow reticulin and collagen deposition, with splenic extramedullary haemopoiesis, suggested rather myelofibrosis.

Familial myelofibrosis occurring in siblings during infancy has not been reported; indeed, there are few reports of familial myelofibrosis at any age. Patakfalvi et al. ${ }^{14}$ described two brothers, one presenting with hepatosplenomegaly at age 69 , while the other developed symptoms of anaemia at 72 years. Decastello ${ }^{15}$ and Bernard et al..$^{16}$ described the occurrence of myelofibrosis in a father and daughter, and Ward and Block ${ }^{17}$ described the father of one myelofibrotic patient having 'cancer of the spleen and then the blood.'

Myelofibrosis in infants is usually idiopathic or associated with acute leukaemia. It is important to attempt to distinguish the idiopathic variety from the illness occurring in our two patients, as the clinical findings appear to be almost identical. Table 3 gives the clinical and laboratory features of 8 patients with well documented idiopathic myelofibrosis occurring during infancy. The age of onset may be the only helpful feature: this ranged from 4 to 30 months, whereas both our patients had presented by age 2 months. Although the laboratory data of these patients are incomplete, 7 of the 8 had normal or increased (1 case) total WBC, while neutropenia was present in only 2 (of 4 patients with differential counts). Platelet count was normal in 4 patients and low in a fifth. In contrast, both our patients presented with severe thrombocytopenia and neutropenia. Lastly, histiocytic infiltration with haemophagocytosis was not mentioned in any of these reports, and although this was not a prominent feature in our patients, it was present, and therefore could be helpful in differentiating the two conditions.

Myelofibrosis in childhood has been described in association with congenital anomalies ${ }^{9}$ and with chromosome abnormalities, although neither of these features has been reported in a familial context. Boxer et al. ${ }^{9}$ reported idiopathic myelofibrosis in a 10-month-old girl who was born with multiple musculoskeletal abnormalities-short right leg with hypoplastic muscles, right foot equinus, small feet with hypoplastic toes, and hypoplastic oblique abdominal musculature. Developmental milestones were delayed, and at 21 months a left-sided seizure occurred. There were no siblings. The course of the disease was chronic and the patient was alive and 


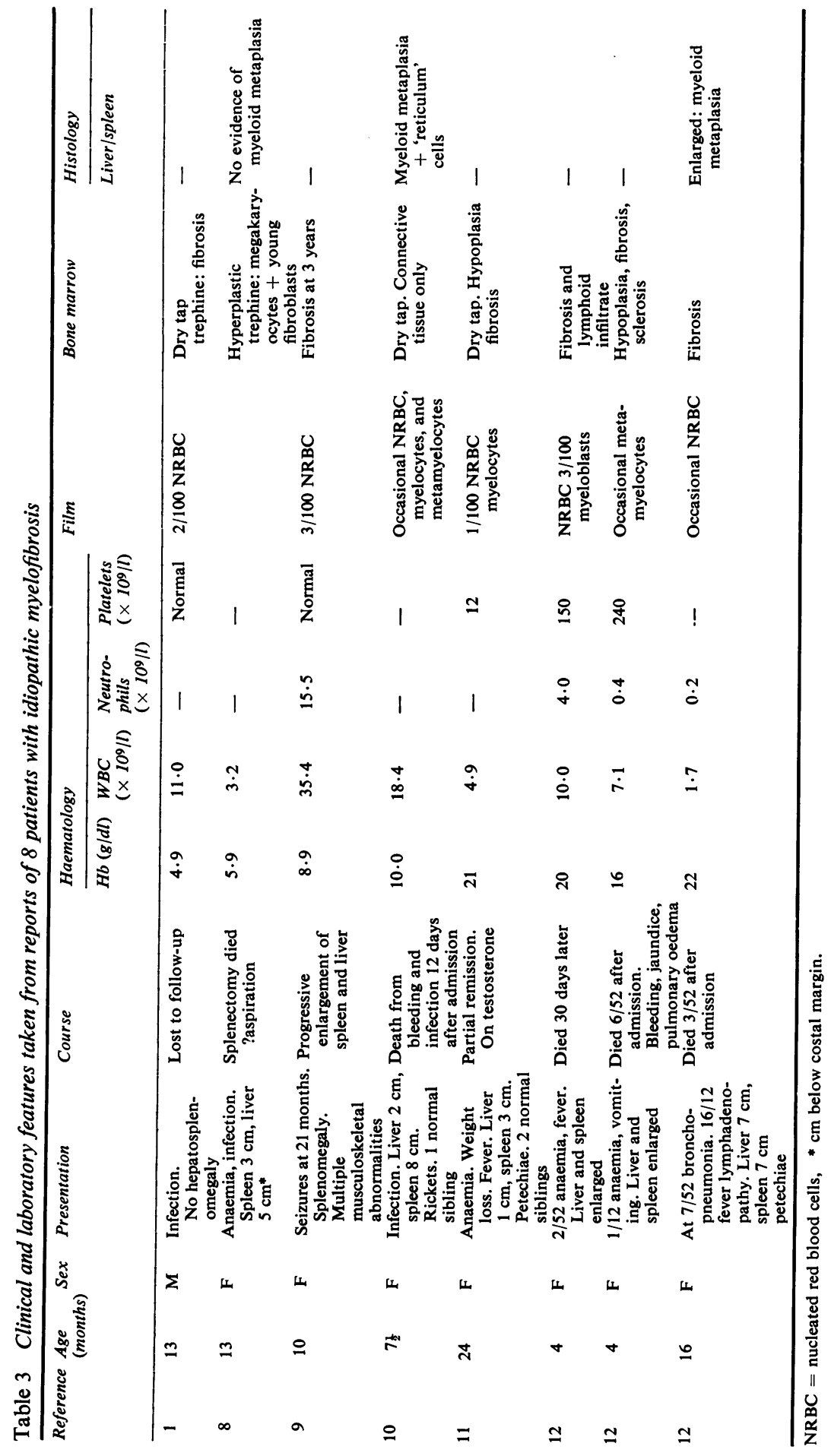


asymptomatic at the time of reporting, 12 years after presentation.

There have been several reports of myelofibrosis occurring in association with Down's syndrome. $^{6-818-19}$ The myelofibrosis in 2 of these patients was secondary to acute myeloid, ${ }^{6}$ or lymphoblastic $^{7}$ leukaemia, whereas 4 other patients ${ }^{818-19}$ suffered from a rapidly progressive myeloproliferative disorder similar to acute leukaemia, with undifferentiated cells in the blood, but with fibrosis of bone marrow rather than leukaemic infiltration.

Myelofibrosis in childhood has been described in association with monosomy of the $\mathrm{C}$ group of chromosomes. ${ }^{20}$ However, the illness in this 5 -yearold negro boy began with recurrent infections at 13 months, and was initially characterised by high WBC. Although the illness terminated fatally with myelofibrosis and myeloid metaplasia, the course appears to be more like that of monosomy 7 , and the myelofibrosis seems likely to have been part of a leukaemic process.

Randall et al. ${ }^{21}$ observed a familial myeloproliferative syndrome in 9 related children: 7 were 1st-cousins and the other 2 were offspring of an apparently unaffected 1st-cousin. The disease was characterised by early onset ( 5 months to 4 years) of pronounced hepatosplenomegaly, anaemia, and thrombocytopenia. However, a prominent feature was leucocytosis, the WBC ranging from 27 to $128 \times 10^{9} / 1$ in every patient except one. Myeloid hyperplasia of the bone marrow was a constant feature and there was no evidence of myelofibrosis or osteosclerosis. These patients therefore appear to have had a disease more akin to chronic myeloid leukaemia. The leucocytosis serves to differentiate this disorder from the one affecting our patients, both of whom had neutropenia.

Our two siblings had a rapidly progressive fatal illness that closely resembled acute idiopathic myelofibrosis of infancy, but with features that suggested familial haemorrhagic reticulosis. Whether one classifies this as familial myelofibrosis or as an atypical variant of familial haemorrhagic reticulosis is less important than that it should be recognised as a familial disorder, with a presumed autosomal recessive mode of inheritance. Appropriate genetic counselling could then be given thereby preventing the tragedy that occurred in this family.

We thank Dr M K Strelling and Dr J N Montgomery, Consultant Paediatricians, Plymouth General Hospital, for permission to publish these cases.

\section{References}

1 Tobin M S, Tan C, Argano S. Myelofibrosis in pediatric age group. NY State J Med 1969; 1 : 1080-3.

2 Churg J, Wachstein M. Osteosclerosis, myelofibrosis, and leukemia. Am J Med Sci 1944; 207: 141-52.

3 Wood E, Andrews C T. Subacute myelosclerosis. Lancet 1949; ii: 739-43.

4 Farber S, Vawter G F. Clinical pathological conference. $J$ Pediatr 1962; 61 : 145-52.

5 Krasilnikoff P A. Myelofibrosis and myeloid leukaemia. Acta Paediatr Scand 1967; 56: 424-9.

6 Okada H, Liu P A, Hoshino T, Yamamoto T, Yamaoka H, Murakami M. Down's syndrome associated with a myeloproliferative disorder. Am J Dis Child 1972; 124: 107-9.

7 Nordan U Z, Humbert J R. Myelofibrosis and acute lymphoblastic leukemia in a child with Down syndrome. J Pediatr 1979; 94: 253-5.

8 Rosenberg H S, Taylor F M. The myeloproliferative syndrome in children. J Pediatr 1958; 52: 407-15.

9 Boxer L A, Camitta B M, Berenburg W, Fanning J P. Myelofibrosis-myeloid metaplasia in childhood. Pediatrics 1975 ; 55: 861-5.

10 Say B, Berkel I. Idiopathic myelofibrosis in an infant. J Pediatr 1964; 64: 580-5.

11 Erf L A, Herbut P A. Primary and secondary myelofibrosis. A clinical and pathological study of 13 cases of fibrosis of the bone marrow. Ann Intern Med 1944; 21: 863-89.

12 Rosenthal N, Erf L A. Clinical observations on osteopetrosis and myelofibrosis. Arch Intern Med 1943; 71: 793-813.

13 Farquhar J W, Claireaux A E. Familial haemophagocytic reticulosis. Arch Dis Child 1952; 27: 519-25.

14 Patakfalvi A, Csete B, Horvath T. Familial myelofibrosis. Haematologia 1969; 3: 217-24.

15 Decastello A. Osteomyelosklerose bei Vater und Tochter. Wien Klin Wochenschr 1954; 66: 655-8.

16 Bernard J, Seligmann M, Loirat C, Chassigneux J, Basch A, Gueudet A. Splenomegalie myeloide familiale. Nouv Rev Fr Hematol 1967; 7: 499-506.

17 Ward H P, Block M H. The natural history of agnogenic myeloid metaplasia and a critical evaluation of its relationship with the myeloproliferative syndrome. Medicine 1971; 50: 357-420.

18 Hillman F, Forrester R M. Myelofibrosis simulating acute leukaemia in a female infant with Down's syndrome. Ir J Med Sci 1968; 1: 167-73.

19 Evans D I K. Acute myelofibrosis in children with Down's syndrome. Arch Dis Child 1975; 50: 458-62.

${ }^{20}$ Holden J D, Garcia F U, Samuels M, Dupin C, Stallworth B, Anderson A. Myelofibrosis with C monosomy of marrow elements in a child. Am J Clin Pathol 1971; 55: 573-9.

21 Randall D L, Reiquam C W, Githens J W, Robinson A. Familial myeloproliferative disease. Am J Dis Child 1965; 110: 479-500.

Correspondence to Dr C A Sieff, Department of Haematology, The Hospital for Sick Children, Great Ormond Street, London WC1N 3JH.

Received 18 September 1979 